\title{
Common Fixed Point Results for Generalized Symmetric Meir-Keeler Contraction
}

\author{
Bhavana Deshpande*, Amrish Handa \\ Department of Mathematics Govt. P. G. Arts \& Science College Ratlam (M. P.) India \\ *Corresponding author: bhavnadeshpande@yahoo.com
}

Received November 13, 2014; Revised December 16, 2014; Accepted January 14, 2015

\begin{abstract}
We introduce the concept of generalized weakly compatibility for the pair $\{\mathrm{F}, \mathrm{G}\}$ of mappings $F, G: X \times X \rightarrow X$ and also introduce the concept of common fixed point of the mappings $F, G: X \times X \rightarrow X$. We establish a common fixed point theorem for generalized weakly compatible pair of mappings $F, G: X \times X \rightarrow X$ without mixed monotone property of any mapping under generalized symmetric Meir-Keeler contraction on a non complete metric space, which is not partially ordered. An example supporting to our result has also been cited. We improve, extend and generalize several known results.
\end{abstract}

Keywords: common fixed point, generalized symmetric meir-keeler contraction, generalized compatibility, generalized weakly compatibility, commuting mapping

Cite This Article: Bhavana Deshpande, and Amrish Handa, "Common Fixed Point Results for Generalized Symmetric Meir-Keeler Contraction." Turkish Journal of Analysis and Number Theory, vol. 3, no. 1 (2015): 7-11. doi: 10.12691/tjant-3-1-2.

\section{Introduction and Preliminaries}

The Banach contraction mapping principle has been generalized in several directions. One of these generalizations, known as the Meir-Keeler fixed point theorem [11], has been obtained by the following more general assumption: for all $\varepsilon>0$ there exists $\delta(\varepsilon)>0$ such that

$$
x, y \in X, \varepsilon \leq d(x, y)<\varepsilon+\delta(\varepsilon) \Rightarrow d(T x, T y)<\varepsilon .
$$

Bhaskar and Lakshmikantham [3] introduced the notion of coupled fixed point, mixed monotone mappings in the setting of single-valued mappings and established some coupled fixed point theorems for a mapping with the mixed monotone property in the setting of partially ordered metric spaces.

In [3], Bhaskar and Lakshmikantham introduced the following.

Definition 1. Let $(X, \preceq)$ be a partially ordered set and endow the product space $X \times X$ with the following partial order:

$$
\begin{aligned}
& (u, v) \preceq(x, y) \Leftrightarrow x \succeq u \text { and } y \preceq v, \\
& \forall(u, v),(x, y) \in X \times X .
\end{aligned}
$$

Definition 2. An element $(x, y) \in X \times X$ is called a coupled fixed point of the mapping $F: X \times X \rightarrow X$ if

$$
F(x, y)=x \text { and } F(y, x)=y \text {. }
$$

Definition 3. Let $(X, \preceq)$ be a partially ordered set. Suppose $F: X \times X \rightarrow X$ be a given mapping. We say that $\mathrm{F}$ has the mixed monotone property if for all $x, y \in X$, we have

$$
x_{1}, x_{2} \in X, x_{1} \preceq x_{2} \Rightarrow F\left(x_{1}, y\right) \preceq F\left(x_{2}, y\right)
$$

and

$$
y_{1}, y_{2} \in X, y_{1} \preceq y_{2} \Rightarrow F\left(x, y_{1}\right) \succeq F\left(x, y_{2}\right) .
$$

Lakshmikantham and Ciric [10] extended the notion of mixed monotone property to mixed g-monotone property and established coupled coincidence point results using a pair of commutative mappings, which generalized the results of Bhaskar and Lakshmikantham [3].

In [10], Lakshmikantham and Ciric introduced the following:

Definition 4. An element $(x, y) \in X \times X$ is called a coupled coincidence point of the mappings $F: X \times X \rightarrow X$ and $g: X \rightarrow X$ if

$$
x=F(x, y)=g(x) \text { and } F(y, x)=g(y) .
$$

Definition 5. an element $(x, y) \in X \times X$ is called a common coupled fixed point of the mappings $F: X \times X \rightarrow X$ and $g: X \rightarrow X$ if

$$
x=F(x, y)=g(x) \text { and } y=F(y, x)=g(y) .
$$

Definition 6. An element $\mathrm{x} 2 \mathrm{X}$ is called a common fixed point of the mappings $F: X \times X \rightarrow X$ and $g: X \rightarrow X$ if

$$
x=g(x)=F(x, x) .
$$

Definition 7. The mappings $F: X \times X \rightarrow X$ and $g: X \rightarrow X$ are said to be commutative if 
$g(F(x, y))=F(g(x), g(y))$, for all $(x, y) \in X \times X .(9)$

Definition 8. Let $(X, \preceq)$ be a partially ordered set. Suppose $F: X \times X \rightarrow X$ and $g: X \rightarrow X$ are given mappings. We say that $\mathrm{F}$ has the mixed g-monotone property if for all $x, y \in X$; we have

$$
x_{1}, x_{2} \in X, g\left(x_{1}\right) \preceq g\left(x_{2}\right) \Rightarrow F\left(x_{1}, y\right) \preceq F\left(x_{2}, y\right)
$$

and

$$
y_{1}, y_{2} \in X, g\left(y_{1}\right) \preceq g\left(y_{2}\right) \Rightarrow F\left(x, y_{1}\right) \succeq F\left(x, y_{2}\right)
$$

If $g$ is the identity mapping on $\mathrm{X}$; then $\mathrm{F}$ satisfies the mixed monotone property.

These results used to study the existence and uniqueness of solution for periodic boundary value problems. Hussain et al. [9] introduced a new concept of generalized compatibility of a pair of mappings $F, G: X \times X \rightarrow X$ defined on a product space and proved some coupled coincidence point results.

In [9], Hussain et al. introduced the following:

Definition 9. An element $(x, y) \in X \times X$ is called a coupled coincidence point of mappings $F, G: X \times X \rightarrow X$ if

$$
F(x, y)=G(x, y) \text { and } F(y, x)=G(y, x) .
$$

Example 10. Let $F, G: \mathbb{R} \times \mathbb{R} \rightarrow \mathbb{R}$ be defined by $\mathrm{F}(\mathrm{x}, \mathrm{y})$ $=x y$ and $\mathrm{G}(\mathrm{x}, \mathrm{y})=2 / 3(\mathrm{x}+\mathrm{y})$ for all $(x, y) \in X \times X$. Note that $(0,0),(1,2)$ and $(2,1)$ are coupled coincidence points of $\mathrm{F}$ and $\mathrm{G}$.

Definition 11. Let $F, G: X \times X \rightarrow X$ be two mappings. We say that the pair $\{\mathrm{F}, \mathrm{G}\}$ is commuting if

$$
\begin{aligned}
& F(G(x, y), G(y, x))=G(F(x, y), F(y, x)), \\
& \text { for all } x, y \in X .
\end{aligned}
$$

Definition 12. Let $F, G: X \times X \rightarrow X$. We say that the pair $\{\mathrm{F}, \mathrm{G}\}$ is generalized compatible if

$$
\begin{aligned}
& \lim _{n \rightarrow \infty} d\left(\begin{array}{l}
F\left(G\left(x_{n}, y_{n}\right), G\left(y_{n}, x_{n}\right)\right), \\
G\left(F\left(x_{n}, y_{n}\right), F\left(y_{n}, x_{n}\right)\right)
\end{array}\right)=0, \\
& \lim _{n \rightarrow \infty} d\left(\begin{array}{l}
F\left(G\left(y_{n}, x_{n}\right), G\left(x_{n}, y_{n}\right)\right), \\
G\left(F\left(y_{n}, x_{n}\right), F\left(x_{n}, y_{n}\right)\right)
\end{array}\right)=0,
\end{aligned}
$$

whenever $\left(\mathrm{x}_{\mathrm{n}}\right)$ and $\left(\mathrm{y}_{\mathrm{n}}\right)$ are sequences in $\mathrm{X}$ such that

$$
\begin{aligned}
& \lim _{n \rightarrow \infty} G\left(x_{n}, y_{n}\right)=\lim _{n \rightarrow \infty} F\left(x_{n}, y_{n}\right)=x, \\
& \lim _{n \rightarrow \infty} G\left(y_{n}, x_{n}\right)=\lim _{n \rightarrow \infty} F\left(y_{n}, x_{n}\right)=y .
\end{aligned}
$$

Obviously, a commuting pair is a generalized compatible but not conversely in general.

Coupled fixed point theory have developed literature, some of the instances of these works are $[1,2,4,5,6,7,8,11,12,13,15]$. Recently Samet et al. [14] claimed that most of the coupled fixed point theorems in the setting of single valued mappings on ordered metric spaces are consequences of well-known fixed point theorems.

In [13], Samet established the coupled fixed points of mixed strict monotone generalized Meir-Keeler operators and also established the existence and uniqueness results for coupled fixed point. Berinde and Pecurar [2] obtained more general coupled fixed point theorems for mixed monotone operators $F: X \times X \rightarrow X$ satisfying a generalized symmetric Meir-Keeler contractive condition.

In this paper, we introduce the concept of generalized weakly compatibility for the pair $\{\mathrm{F}, \mathrm{G}\}$ of mappings $F, G: X \times X \rightarrow X$ and also introduce the concept of common fixed point of the mappings $F, G: X \times X \rightarrow X$. We establish a common fixed point theorem for generalized weakly compatible pair of mappings $F, G: X \times X \rightarrow X$ without mixed monotone property of any mapping under generalized symmetric Meir-Keeler contraction on a non complete metric space, which is not partially ordered. We also give an example to support our result presented here. We extend and generalize the results of Berinde and Pecurar [2], Bhaskar and Lakshmikantham [3], Meir and Keeler [11], Samet [13] and many other results in the existing literature.

\section{Main Results}

First, we introduce the following:

Definition 13. An element $x \in X$ is called a common fixed point of the mappings $F, G: X \times X \rightarrow X$ if

$$
x=F(x, x)=G(x, x) .
$$

Definition 14. Let $X$ be a non-empty set. The mappings $F, G: X \times X \rightarrow X$ are called generalized weakly compatible mappings if $\mathrm{F}(\mathrm{x}, \mathrm{y})=\mathrm{G}(\mathrm{x}, \mathrm{y}), \mathrm{F}(\mathrm{y}, \mathrm{x})=\mathrm{G}(\mathrm{y}, \mathrm{x})$ implies that $G(F(x, y), F(y, x))=F(G(x, y), G(y, x))$, $\mathrm{G}(\mathrm{F}(\mathrm{y}, \mathrm{x}), \mathrm{F}(\mathrm{x}, \mathrm{y}))=\mathrm{F}(\mathrm{G}(\mathrm{y}, \mathrm{x}), \mathrm{G}(\mathrm{x}, \mathrm{y}))$, for all $(x, y) \in X$. Obviously, a generalized compatible pair is generalized weakly compatible but converse is not true in general.

Example 15. Let (X, d) be a usual metric space where $X=\left\{0,1, \frac{1}{2}, \frac{1}{3}, \cdots, \frac{1}{n}, \cdots\right\}$. Define $F, G: X \times X \rightarrow X$ by

$$
F(x, y)=\left\{\begin{array}{c}
\frac{1}{(2 n+1)^{4}},(x, y)=\left(\frac{1}{2 n}, \frac{1}{2 n}\right) \\
0, \text { otherwise }
\end{array}\right.
$$

and

$$
G(x, y)=\left\{\begin{array}{c}
1,(x, y)=\left(\frac{1}{2 n+1}, \frac{1}{2 n+1}\right) \\
\frac{1}{2 n+1},(x, y)=\left(\frac{1}{2 n}, \frac{1}{2 n}\right) \\
0, \text { otherwise }
\end{array}\right.
$$

Let $x_{n}=y_{n}=\frac{1}{2 n}$. Then, we have

$$
G\left(x_{n}, y_{n}\right)=\frac{1}{2 n+1} \rightarrow 0, F\left(x_{n}, y_{n}\right)=\frac{1}{(2 n+1)^{4}} \rightarrow 0
$$

as $n \rightarrow \infty$, but

$$
\lim _{n \rightarrow \infty} d\left(\begin{array}{l}
F\left(G\left(x_{n}, y_{n}\right), G\left(y_{n}, x_{n}\right)\right), \\
G\left(F\left(x_{n}, y_{n}\right), F\left(y_{n}, x_{n}\right)\right)
\end{array}\right)=d(0,1) \nrightarrow 0 .
$$


So $\mathrm{F}$ and $\mathrm{G}$ are not generalized compatible. From $\mathrm{F}(\mathrm{x}, \mathrm{y})$ $=\mathrm{G}(\mathrm{x}, \mathrm{y}), \mathrm{F}(\mathrm{y}, \mathrm{x})=\mathrm{G}(\mathrm{y}, \mathrm{x})$, we can get $(\mathrm{x}, \mathrm{y})=(0,0)$ and we have $\mathrm{G}(\mathrm{F}(0,0), \mathrm{F}(0,0))=\mathrm{F}(\mathrm{G}(0,0), \mathrm{G}(0,0)), \mathrm{G}(\mathrm{F}(0,0)$, $\mathrm{F}(0,0))=\mathrm{F}(\mathrm{G}(0,0), \mathrm{G}(0,0))$, which implies that $\mathrm{F}$ and $\mathrm{G}$ are generalized weakly compatible.

Theorem 16. Let $(\mathrm{X}, \mathrm{d})$ be a metric space. Assume $F, G: X \times X \rightarrow X$ be two generalized weakly compatible mappings and for each $\varepsilon>0$, there exists $\delta(\varepsilon)>0$ such that $\varepsilon \leq \frac{d(G(x, y), G(u, v))+d(G(y, x), G(v, u))}{2} \leq \varepsilon+\delta(\varepsilon)$ implies

$$
\frac{d(F(x, y), F(u, v))+d(F(y, x), F(v, u))}{2} \leq \varepsilon
$$

for all $x, y, u, v \in X$. Suppose that for any $x, y \in X$, there exist $u, v \in X$ such that

$$
F(x, y)=G(u, v) \text { and } F(y, x)=G(v, u)
$$

Suppose that $F(X \times X)$ or $G(X \times X)$ is complete. Then there exists a unique $x \in X$ such that $\mathrm{x}=\mathrm{G}(\mathrm{x}, \mathrm{x})=$ $\mathrm{F}(\mathrm{x}, \mathrm{x})$.

Proof. Let $\mathrm{x}_{0}, \mathrm{y}_{0}$ be two arbitrary points in $\mathrm{X}$. From (15); we can choose $x_{1}, y_{1} \in X$ such that

$$
\begin{aligned}
& G\left(x_{1}, y_{1}\right)=F\left(x_{0}, y_{0}\right) \\
& \text { and } \\
& G\left(y_{1}, x_{1}\right)=F\left(y_{0}, x_{0}\right) .
\end{aligned}
$$

Continuing this process, we can construct sequences $\left\{\mathrm{x}_{\mathrm{n}}\right\}$ and $\left\{\mathrm{y}_{\mathrm{n}}\right\}$ in $\mathrm{X}$ such that

$$
\begin{aligned}
& G\left(x_{n+1}, y_{n+1}\right)=F\left(x_{n}, y_{n}\right) \\
& \text { and } \\
& G\left(y_{n+1}, x_{n+1}\right)=F\left(y_{n}, x_{n}\right), \\
& \text { for all } n \geq 0 .
\end{aligned}
$$

The proof is divided into 4 steps.

Step 1. Prove that $\left\{\mathrm{G}\left(\mathrm{x}_{\mathrm{n}}, \mathrm{y}_{\mathrm{n}}\right)\right\}$ and $\left\{\mathrm{G}\left(\mathrm{y}_{\mathrm{n}}, \mathrm{x}_{\mathrm{n}}\right)\right\}$ are Cauchy sequences.

Now, by (14), for each $\varepsilon>0$, there exists $\delta(\varepsilon)>0$ such that

$$
\varepsilon \leq \frac{d(G(x, y), G(u, v))+d(G(y, x), G(v, u))}{2} \leq \varepsilon+\delta(\varepsilon)
$$

implies

$$
\frac{d(F(x, y), F(u, v))+d(F(y, x), F(v, u))}{2} \leq \varepsilon
$$

Condition (17) implies the strict contractive condition

$$
\begin{aligned}
& \frac{d(F(x, y), F(u, v))+d(F(y, x), F(v, u))}{2} \\
& <\frac{d(G(x, y), G(u, v))+d(G(y, x), G(v, u))}{2},
\end{aligned}
$$

for $G(x, y) \leq G(u, v)$ and $G(y, x) \geq G(v, u)$. Thus, by (18), we have

$$
\begin{aligned}
& d\left(G\left(x_{n+1}, y_{n+1}\right), G\left(x_{n}, y_{n}\right)\right) \\
& \frac{+d\left(G\left(y_{n+1}, x_{n+1}\right), G\left(y_{n}, x_{n}\right)\right)}{2} \\
& d\left(F\left(x_{n}, y_{n}\right), F\left(x_{n-1}, y_{n-1}\right)\right) \\
& =\frac{+d\left(F\left(y_{n}, x_{n}\right), F\left(y_{n-1}, x_{n-1}\right)\right)}{2} \\
& d\left(G\left(x_{n}, y_{n}\right), G\left(x_{n-1}, y_{n-1}\right)\right) \\
& <\frac{+d\left(G\left(y_{n}, x_{n}\right), G\left(y_{n-1}, x_{n-1}\right)\right)}{2}
\end{aligned}
$$

which shows that the sequence of nonnegative numbers $\left\{\Delta_{n}\right\}_{n=0}^{\infty}$ given by

$$
\begin{gathered}
d\left(G\left(x_{n}, y_{n}\right), G\left(x_{n-1}, y_{n-1}\right)\right) \\
\Delta_{n}=\frac{+d\left(G\left(y_{n}, x_{n}\right), G\left(y_{n-1}, x_{n-1}\right)\right)}{2},
\end{gathered}
$$

is non-increasing, Therefore, there exists some $\varepsilon \geq 0$ such that

$$
\lim _{n \rightarrow \infty} \Delta_{n}=\lim _{n \rightarrow \infty} \frac{1}{2}\left[\begin{array}{l}
d\left(G\left(x_{n}, y_{n}\right), G\left(x_{n-1}, y_{n-1}\right)\right) \\
+d\left(G\left(y_{n}, x_{n}\right), G\left(y_{n-1}, x_{n-1}\right)\right)
\end{array}\right]=\varepsilon .
$$

We shall prove that $\varepsilon=0$. Suppose, to the contrary, that $\varepsilon>0$. Then there exists a positive integer p such that

$$
\varepsilon<\Delta_{p}<\varepsilon+\delta(\varepsilon)
$$

which, by (17); implies

$$
\begin{aligned}
& d\left(F\left(x_{p}, y_{p}\right), F\left(x_{p-1}, y_{p-1}\right)\right) \\
& \frac{+d\left(F\left(y_{p}, x_{p}\right), F\left(y_{p-1}, x_{p-1}\right)\right)}{2}<\varepsilon
\end{aligned}
$$

it follows, by (16) and (19); that

$$
\begin{array}{r}
d\left(G\left(x_{p+1}, y_{p+1}\right), G\left(x_{p}, y_{p}\right)\right) \\
\Delta_{p+1}=\frac{+d\left(G\left(y_{p+1}, x_{p+1}\right), G\left(y_{p}, x_{p}\right)\right)}{2}
\end{array}
$$

which is a contradiction. Thus $\varepsilon=0$ and hence

$$
\lim _{n \rightarrow \infty} \Delta_{n}=\lim _{n \rightarrow \infty} \frac{1}{2}\left[\begin{array}{l}
d\left(G\left(x_{n}, y_{n}\right), G\left(x_{n-1}, y_{n-1}\right)\right) \\
+d\left(G\left(y_{n}, x_{n}\right), G\left(y_{n-1}, x_{n-1}\right)\right)
\end{array}\right]=0 .
$$

Let now $\varepsilon>0$ be arbitrary and $\delta(\varepsilon)$ the corresponding value from the hypothesis of our theorem. By (20), there exists a positive integer $\mathrm{k}$ such that

$$
\Delta_{k+1}=\frac{1}{2}\left[\begin{array}{l}
d\left(G\left(x_{k+1}, y_{k+1}\right), G\left(x_{k}, y_{k}\right)\right) \\
+d\left(G\left(y_{k+1}, x_{k+1}\right), G\left(y_{k}, x_{k}\right)\right)
\end{array}\right]<\delta(\varepsilon) .
$$

For this fixed number $\mathrm{k}$, consider now the set $\mathrm{A}_{\mathrm{k}}=$ $\left\{(\mathrm{G}(\mathrm{x}, \mathrm{y}), \mathrm{G}(\mathrm{y}, \mathrm{x})): \mathrm{G}\left(\mathrm{x}_{\mathrm{k}}, \mathrm{y}_{\mathrm{k}}\right) \leq \mathrm{G}(\mathrm{x}, \mathrm{y}), \mathrm{G}(\mathrm{y}, \mathrm{x}) \geq \mathrm{G}\left(\mathrm{y}_{\mathrm{k}}, \mathrm{x}_{\mathrm{k}}\right)\right.$, $1 / 2\left[\mathrm{~d}\left(\mathrm{G}\left(\mathrm{x}_{\mathrm{k}}, \mathrm{y}_{\mathrm{k}}\right), \mathrm{G}(\mathrm{x}, \mathrm{y})\right)+\mathrm{d}\left(\mathrm{G}\left(\mathrm{y}_{\mathrm{k}}, \mathrm{x}_{\mathrm{k}}\right), \mathrm{G}(\mathrm{y}, \mathrm{x})\right)\right]<\varepsilon+\delta(\varepsilon)$. By (21), $A_{k} \neq \varnothing$. We claim that

$$
(G(x, y), G(y, x)) \in A_{k} \Rightarrow(F(x, y), F(y, x)) \in A_{k} .
$$


Let $(G(x, y), G(y, x)) \in A_{k}$. Then

$\frac{d\left(G\left(x_{k}, y_{k}\right), G(x, y)\right)+d\left(G\left(y_{k}, x_{k}\right), G(y, x)\right)}{2}<\varepsilon$.

which, by (14), implies

$\frac{d\left(F\left(x_{k}, y_{k}\right), F(x, y)\right)+d\left(F\left(y_{k}, x_{k}\right), F(y, x)\right)}{2}<\varepsilon$.

Now, by (21) and (24), we have

$\frac{d\left(G\left(x_{k}, y_{k}\right), G(x, y)\right)+d\left(G\left(y_{k}, x_{k}\right), G(y, x)\right)}{2}$

$\leq \frac{d\left(G\left(x_{k}, y_{k}\right), G\left(x_{k}, y_{k}\right)\right)+d\left(G\left(y_{k}, x_{k}\right), G\left(y_{k}, x_{k}\right)\right)}{2}$

$+\frac{d\left(F\left(x_{k}, y_{k}\right), F(x, y)\right)+d\left(F\left(y_{k}, x_{k}\right), F(y, x)\right)}{2}$

$d\left(G\left(x_{k}, y_{k}\right), G\left(x_{k+1}, y_{k+1}\right)\right)$

$\leq \frac{+d\left(G\left(y_{k}, x_{k}\right), G\left(y_{k+1}, x_{k+1}\right)\right)}{2}$

$+\frac{d\left(F\left(x_{k}, y_{k}\right), F(x, y)\right)+d\left(F\left(y_{k}, x_{k}\right), F(y, x)\right)}{2}$

$<\varepsilon+\delta(\varepsilon)$

Thus $(F(x, y), F(y, x)) \in A_{k}$. Again

$\frac{d\left(G\left(x_{k}, y_{k}\right), G\left(x_{k+1}, y_{k+1}\right)\right)+d\left(G\left(y_{k}, x_{k}\right), G\left(y_{k+1}, x_{k+1}\right)\right)}{2}$

$\leq \frac{d\left(G\left(x_{k}, y_{k}\right), G(x, y)\right)+d\left(G\left(y_{k}, x_{k}\right), G(y, x)\right)}{2}$

$+\frac{d\left(F(x, y), F\left(x_{k+1}, y_{k+1}\right)\right)+d\left(F(y, x), F\left(y_{k+1}, x_{k+1}\right)\right)}{2}$

$<2(\varepsilon+\delta(\varepsilon))$.

Thus $\left(G\left(x_{k+1}, y_{k+1}\right), G\left(y_{k+1}, x_{k+1}\right)\right) \in A_{k} \quad$ and $\quad$ by induction,

$$
\left(G\left(x_{k+1}, y_{k+1}\right), G\left(y_{k+1}, x_{k+1}\right)\right) \in A_{k},
$$

for all $n>k$.

This implies that for all $\mathrm{n}, \mathrm{m}>\mathrm{k}$, we have

$$
\begin{aligned}
& \frac{d\left(G\left(x_{n}, y_{n}\right), G\left(x_{m}, y_{m}\right)\right)+d\left(G\left(y_{n}, x_{n}\right), G\left(y_{m}, x_{m}\right)\right)}{2} \\
& \leq \frac{d\left(G\left(x_{n}, y_{n}\right), G\left(x_{k}, y_{k}\right)\right)+d\left(G\left(y_{n}, x_{n}\right), G\left(y_{k}, x_{k}\right)\right)}{2} \\
& +\frac{d\left(G\left(x_{k}, y_{k}\right), G\left(x_{m}, y_{m}\right)\right)+d\left(G\left(y_{k}, x_{k}\right), G\left(y_{m}, x_{m}\right)\right)}{2} \\
& <2(\varepsilon+\delta(\varepsilon))=4 \varepsilon .
\end{aligned}
$$

This shows that $\left\{G\left(x_{n}, y_{n}\right)\right\}_{n=0}^{\infty}$ and $\left\{G\left(y_{n}, x_{n}\right)\right\}_{n=0}^{\infty}$ are Cauchy sequences in $\mathrm{X}$.

Step 2. Prove that $G$ and $F$ have a coupled coincidence point.

Since $G(X \times X)$ is complete, then there exist $x, y \in G(X \times X)$ and $(a, b) \in X \times X$ such that

$$
\begin{aligned}
& \lim _{n \rightarrow \infty} G\left(x_{n}, y_{n}\right)=\lim _{n \rightarrow \infty} F\left(x_{n}, y_{n}\right)=G(a, b)=x, \\
& \lim _{n \rightarrow \infty} G\left(y_{n}, x_{n}\right)=\lim _{n \rightarrow \infty} F\left(y_{n}, x_{n}\right)=G(b, a)=y .
\end{aligned}
$$

Now, by (18), we have

$$
\begin{aligned}
& \frac{d\left(F\left(x_{n}, y_{n}\right), F(a, b)\right)+d\left(F\left(y_{n}, x_{n}\right), F(b, a)\right)}{2} \\
& <\frac{d\left(G\left(x_{n}, y_{n}\right), G(a, b)\right)+d\left(G\left(y_{n}, x_{n}\right), G(b, a)\right)}{2} .
\end{aligned}
$$

Taking limit as $\mathrm{n} \rightarrow 1$ in the above inequality and using (25), we have

$$
d(G(a, b), F(a, b))=0 \text { and } d(G(b, a), F(b, a))=0,
$$

which implies that

$$
F(a, b)=G(a, b)=x \text { and } F(b, a)=G(b, a)=y .
$$

Since $\mathrm{F}$ and $\mathrm{G}$ are generalized weakly compatible, we get that

$$
\begin{aligned}
& G(F(a, b), F(b, a))=F(G(a, b), G(b, a)), \\
& G(F(b, a), F(a, b))=F(G(b, a), G(a, b)),
\end{aligned}
$$

which implies that

$$
G(x, y)=F(x, y) \text { and } G(y, x)=F(y, x),
$$

that is, $(\mathrm{x}, \mathrm{y})$ is a coupled coincidence point of $\mathrm{F}$ and $\mathrm{G}$.

Step 3. Prove that $\mathrm{G}(\mathrm{x}, \mathrm{y})=\mathrm{y}$ and $\mathrm{G}(\mathrm{y}, \mathrm{x})=\mathrm{x}$.

If, not. Then by (18), we have

$$
\begin{aligned}
& \frac{d\left(F(x, y), F\left(y_{n}, x_{n}\right)\right)+d\left(F(y, x), F\left(x_{n}, y_{n}\right)\right)}{2} \\
& <\frac{d\left(G(x, y), G\left(y_{n}, x_{n}\right)\right)+d\left(G(y, x), G\left(x_{n}, y_{n}\right)\right)}{2} .
\end{aligned}
$$

Letting $n \rightarrow \infty$ in the above inequality and using (25), we have

$$
\begin{aligned}
& \frac{d(G(x, y), y)+d(G(y, x), x)}{2} \\
& <\frac{d(G(x, y), y)+d(G(y, x), x)}{2},
\end{aligned}
$$

which is a contradiction. Thus we must have $G(x, y)=y$ and $\mathrm{G}(\mathrm{y}, \mathrm{x})=\mathrm{x}$.

Step 4. Prove that $\mathrm{x}=\mathrm{y}$.

If, not. Then by (18), we have

$$
\begin{aligned}
& \frac{d\left(F\left(x_{n}, y_{n}\right), F\left(y_{n}, x_{n}\right)\right)+d\left(F\left(y_{n}, x_{n}\right), F\left(x_{n}, y_{n}\right)\right)}{2} \\
& <\frac{d\left(G\left(x_{n}, y_{n}\right), G\left(y_{n}, x_{n}\right)\right)+d\left(G\left(y_{n}, x_{n}\right), G\left(x_{n}, y_{n}\right)\right)}{2} .
\end{aligned}
$$

Letting $n \rightarrow \infty$ in the above inequality and using (25), we get

$$
\frac{d(x, y)+d(y, x)}{2}<\frac{d(x, y)+d(y, x)}{2},
$$

which is a contradiction. Thus $\mathrm{x}=\mathrm{y}$. 
Example 17. Suppose that $\mathrm{X}=\mathbb{R}$, equipped with the usual metric $d: X \times X \rightarrow[0,+\infty)$. Let $F, G: X \times X \rightarrow X$ be defined as

$$
F(x, y)=\left\{\begin{array}{c}
\frac{x^{2}-y^{2}}{3}, \text { if } x \geq y, \\
0, \text { if } x<y,
\end{array}\right.
$$

and

$$
G(x, y)=\left\{\begin{array}{c}
x^{2}-y^{2}, \text { if } x \geq y \\
0, \text { if } x<y
\end{array}\right.
$$

From $F(x, y)=G(x, y), F(y, x)=G(y, x)$, we can get $(x$, $y)=(0,0)$ and we have $\mathrm{G}(\mathrm{F}(0,0), \mathrm{F}(0,0))=\mathrm{F}(\mathrm{G}(0,0)$, $\mathrm{G}(0,0)), \mathrm{G}(\mathrm{F}(0,0), \mathrm{F}(0,0))=\mathrm{F}(\mathrm{G}(0,0), \mathrm{G}(0,0))$, which implies that $\mathrm{F}$ and $\mathrm{G}$ are generalized weakly compatible.

Now, we prove that for any $x, y \in X$, there exist $u, v \in X$ such that

$$
F(x, y)=G(u, v) \text { and } F(y, x)=G(v, u) .
$$

Let $(x, y)(u, v) \in X \times X$ be fixed. We consider the following cases:

Case 1: If $x=y$, then we have $F(x, y)=0=G(x, y)$ and $\mathrm{F}(\mathrm{y}, \mathrm{x})=0=\mathrm{G}(\mathrm{y}, \mathrm{x})$.

Case 2: If $x>y$, then we have $F(x, y)=\frac{x^{2}-y^{2}}{3}=G\left(\frac{x}{\sqrt{3}}, \frac{y}{\sqrt{3}}\right) \quad$ and $F(y, x)=0=G\left(\frac{y}{\sqrt{3}}, \frac{x}{\sqrt{3}}\right)$.

Case 3: If $\mathrm{x}<\mathrm{y}$, then we have $F(x, y)=0=G\left(\frac{x}{\sqrt{3}}, \frac{y}{\sqrt{3}}\right)$ and $F(y, x)=\frac{y^{2}-x^{2}}{3}=G\left(\frac{y}{\sqrt{3}}, \frac{x}{\sqrt{3}}\right)$. Now, we shall show that the mappings $\mathrm{F}$ and $\mathrm{G}$ satisfy the condition (14): For each $x, y, u, v \in X \times X$, we have

$$
\begin{aligned}
& \varepsilon \leq \frac{d(G(, y), G(u, v))+d(G(y, x), G(v, u))}{2} \\
& \leq \varepsilon+\delta(\varepsilon) .
\end{aligned}
$$

Then

$$
\begin{aligned}
& \frac{d(F(x, y), F(u, v))+d(F(y, x), F(v, u))}{2} \\
& =\frac{1}{2}\left[\left|\frac{x^{2}-y^{2}}{3}-\frac{u^{2}-v^{2}}{3}\right|+\left|\frac{y^{2}-x^{2}}{3}-\frac{v^{2}-u^{2}}{3}\right|\right] \\
& =\frac{1}{6}[|G(x, y)-G(u, v)|+|G(y, x)-G(v, u)|] \\
& =\frac{1}{3}\left[\frac{d(G(x, y), G(u, v))+d(G(y, x), G(v, u))}{2}\right] \\
& =\frac{1}{3}(\varepsilon+\delta(\varepsilon))<\varepsilon .
\end{aligned}
$$

Thus the contractive condition (14) is satisfied for all $x, y, u, v \in X$. In addition, all the other conditions of Theorem 16 are satisfied and 0 is a unique common fixed point of $F$ and $G$.

Corollary 18. Let $(\mathrm{X}, \mathrm{d})$ be a metric space. Assume $F, G: X \times X \rightarrow X$ be two generalized compatible mappings satisfying (14), (15) and $F(X \times X)$ or $G(X \times X)$ is complete. Then there exists a unique $x \in X$ such that $\mathrm{x}=\mathrm{G}(\mathrm{x}, \mathrm{x})=\mathrm{F}(\mathrm{x}, \mathrm{x})$.

Corollary 19. Let $(\mathrm{X}, \mathrm{d})$ be a metric space. Assume $F, G: X \times X \rightarrow X$ be two commuting mappings satisfying (14), (15) and $F(X \times X)$ or $G(X \times X)$ is complete. Then there exists a unique $x \in X$ such that $\mathrm{x}=$ $\mathrm{G}(\mathrm{x}, \mathrm{x})=\mathrm{F}(\mathrm{x}, \mathrm{x})$.

\section{References}

[1] V. Berinde, Coupled fixed point theorems for $\varphi$-contractive mixed monotone mappings in partially ordered metric spaces, Nonlinear Anal. 75 (2012), 3218-3228.

[2] V. Berinde and M. Pecurar, Coupled fixed point theorems for generalized symmetric Meir-Keeler contractions in ordered metric spaces, Fixed Point Theory Appl. 2012, 2012: 115.

[3] T. G. Bhaskar and V. Lakshmikantham, Fixed point theorems in partially ordered metric spaces and applications, Nonlinear Anal. 65 (7) (2006), 1379-1393.

[4] L. Ciric, B. Damjanovic, M. Jleli and B. Samet, Coupled fixed point theorems for generalized Mizoguchi-Takahashi contractions with applications, Fixed Point Theory Appl. 2012, 2012:51.

[5] B. Deshpande and A. Handa, Nonlinear mixed monotonegeneralized contractions on partially ordered modified intuitionistic fuzzy metric spaces with application to integral equations, Afr. Mat.

[6] B. Deshpande and A. Handa, Application of coupled fixed point technique in solving integral equations on modified intuitionistic fuzzy metric spaces, Adv. Fuzzy Syst. Volume 2014, Article ID 348069, 11 pages. 10

[7] H. S. Ding, L. Li and S. Radenovic, Coupled coincidence point theorems for generalized nonlinear contraction in partially ordered metric spaces, Fixed Point Theory Appl. 2012, 2012:96.

[8] M. E. Gordji, E. Akbartabar, Y. J. Cho and M. Ramezani, Coupled common fixed point theorems for mixed weakly monotone mappings in partially ordered metric spaces, Fixed Point Theory Appl. 2012, 2012:95.

[9] N. Hussain, M. Abbas, A. Azam and J. Ahmad, Coupled coincidence point results for a generalized compatible pair with applications, Fixed Point Theory Appl. 2014, 2014: 62.

[10] V. Lakshmikantham and L. Ciric, Coupled fixed point theorems for nonlinear contractions in partially ordered metric spaces, Nonlinear Anal. 70 (12) (2009), 4341-4349.

[11] A. Meir and E. Keeler, A theorem on contraction mappings, J. Math. Anal. Appl. 28 (1969), 326-329.

[12] M. Mursaleen, S. A. Mohiuddine and R. P. Agarwal, Coupled fixed point theorems for alpha-psi contractive type mappings in partially ordered metric spaces, Fixed Point Theory Appl. 2012, 2012: 228.

[13] B. Samet, Coupled fixed point theorems for a generalized MeirKeeler contraction in partially ordered metric spaces, Nonlinear Anal. 72, 4508-4517 (2010).

[14] B. Samet, E. Karapinar, H. Aydi and V. C. Rajic, Discussion on some coupled fixed point theorems, Fixed Point Theory Appl. 2013, 2013:50.

[15] W. Sintunavarat, P. Kumam and Y. J. Cho, Coupled fixed point theorems for nonlinear contractions without mixed monotone property, Fixed Point Theory Appl. 2012, 2012: 170. 